\title{
Application of terrestrial laser scanning for detection of ground surface deformation in small mud volcano (Murono, Japan)
}

\author{
Yuichi S. Hayakawa ${ }^{*}$, Shigekazu Kusumoto ${ }^{2}$ and Nobuhisa Matta ${ }^{3}$
}

\begin{abstract}
We perform terrestrial laser scanning (TLS) to detect changes in surface morphology of a mud volcano in Murono, north-central Japan. The study site underwent significant deformation by a strong earthquake in 2011, and the surface deformation has continued in the following years. The point cloud datasets were obtained by TLS at three different times in 2011, 2013 and 2014. Those point clouds were aligned by cloud-based registration, which minimizes the closest point distance of point clouds of unchanged ground features, and the TLS-based point cloud data appear to be suitable for detecting centimeter-order deformations in the central domain of the mud volcano, as well as for measurements of topographic features including cracks of paved ground surface. The spatial patterns and accumulative amount of the vertical deformation during 2011-2014 captured by TLS correspond well with those previously reported based on point-based leveling surveys, supporting the validity of TLS survey.
\end{abstract}

Keywords: Mud volcano, Deformation, TLS (terrestrial laser scanning), Point cloud, DEM (digital elevation model)

\section{Background}

Geodetic study often requires highly accurate and precise measurements of ground surface positions, and several approaches have been developed for the detection of ground surface deformation including leveling, total station and global satellite navigation system (GNSS) (e.g., Hubbard and Glasser 2005; Mottershead et al. 2008; McCormac et al. 2012). However, such previous approaches have often been limited to some specific points of measurement, and if one would like to know the characteristics of spatially variable deformation of ground surface, increasing the density of measurement points could be one solution which requires significant time of measurement in the field, or one needs to introduce InSAR (e.g., Antonielli et al. 2014).

Among else, terrestrial laser scanning (TLS) has been an emerging approach for the measurement of spatially varying topographic changes in environmental sciences

\footnotetext{
*Correspondence: hayakawa@csis.u-tokyo.ac.jp

${ }^{1}$ Center for Spatial Information Science, The University of Tokyo, 5-1-5

Kashiwanoha, Kashiwa, Chiba 277-8568, Japan

Full list of author information is available at the end of the article
}

(Heritage and Hetherington 2007; Heritage and Large 2009). TLS enables accurate measurements of highly dense point cloud on the ground surface, and detection of changes in surface morphology is feasible when multiple time series of measurement data are obtained. Although the accuracy assessment is crucial for determining the level of detection (Lane et al. 2003; Milan et al. 2011), the validity of application of TLS for geodetic measurements would be promising (DeLong et al. 2015).

Here, we examine the applicability of TLS measurement for an active mud volcano where both gradual and abrupt surficial changes have been observed with precise measurements using the leveling method (Kusumoto et al. 2014, 2015). Topographic features are explored from the high-definition data by TLS, and changes in ground surface elevation are examined by multi-temporal TLS measurements. Because the TLS approach generally provides morphological information of the surface of a target object (Heritage and Large, 2009) and not for its internal structures, here we focus on the surficial deformation of the mud volcano, whose amount is on the order of centimeters in a year (Kusumoto et al. 2014). 


\section{Methods}

\section{Study area}

The study site is an active mud volcano in Murono area, Niigata Prefecture in north-central Japan (Fig. 1). The mud volcano locates at $316 \mathrm{~m}$ a.s.l. near an anticline limb of the Naradate syncline (e.g., Noda 1962), with a small coverage area of approximately $130 \mathrm{~m} \times 180 \mathrm{~m}$. The surrounding area is characterized by many fold structures in the NE-SW direction and is known as one of the most important petroleum-producing areas in Japan. The mud volcano has therefore been attracted many interests for geophysical and geochemical researches (e.g., Onishi et al. 2009; Shinya and Tanaka 2009; Suzuki et al. 2009; Etiope et al. 2011). The domain of the mud volcano is used as a practice course for automobile driving, and many areas are paved but others are covered with vegetation including grass and trees (Fig. 1b).

Significant deformations of the mud volcano have been observed by several large earthquakes in the area. Onishi et al. (2009) reported a vertical movement of up to $400 \mathrm{~mm}$ in the area before and after the Niigataken Chuetsu-oki Earthquake in 2007 (Mj = 6.8) whose epicenter is $44 \mathrm{~km}$ away, using a GNSS survey. Such remarkable vertical deformation was also observed by the North Nagano Prefecture Earthquake ( $\mathrm{Mj}=6.7$, epicenter $16 \mathrm{~km}$ away) in March 2011 (Matta et al. 2012), as well as by the Nagano-ken Kamishiro Fault Earthquake $(\mathrm{Mj}=6.7,76 \mathrm{~km}$ away) in November 2014 (Kusumoto et al. 2015). Furthermore, although the amount is less than those caused by large earthquakes, inter-seismic uplift of the mud volcano has also been observed by precise leveling survey at approximately $50 \mathrm{~mm}$ (Kusumoto et al. 2014).

However, such vertical movements have only been observed at sparse points by GNSS or leveling survey, and the detailed spatial characteristics of the deformation have been unknown. The dense measurement by TLS is therefore applied to reveal the spatial distribution of vertical displacements in the study area. The target of measurement is approximately $50 \mathrm{~m} \times 60 \mathrm{~m}$ zone (Fig. 1b,c), where vertical displacement has been frequently occurring (Kusumoto et al. 2014, 2015).

\section{Data acquisition and processing}

On-site measurements using TLS were taken three times: June 2011 (110623), December 2013 (131205) and December 2014 (141204), where the date of survey is expressed as YYMMDD. The first measurement (110623) was just after the North Nagano Prefecture Earthquake occurred on March 12, 2011, whereas the third (141204) was after the Nagano-ken Kamishiro Fault Earthquake on November 22, 2014. There was no significant earthquake between the first (110623) and second (131205) measurements.

For the first measurement (110623), a medium-range, time-of-flight-type terrestrial laser scanner GLS-1500 by Topcon Co. was used (Fig. 2a). This device has an ability of measuring up to $500 \mathrm{~m}$ distance with a $1-\mathrm{mm}$ minimum pitch of laser pulse, with a scan frequency of 30,000 points per second (Topcon 2010). The range accuracy of the laser measurement is $4 \mathrm{~mm}$ within $150 \mathrm{~m}$ of distance. The weight of the device is $16 \mathrm{~kg}$ (without batteries). Initial data management and basic processing of the point cloud obtained with this device are performed using Topcon ScanMaster v.2.0, which is bundled with the scanner. For the following measurements (131205 and 141204), we use a lightweight, phase-based short-range scanner Trimble TX5. This device is more suitable for such shortrange measurements with denser point acquisition with an ability of measuring up to $120 \mathrm{~m}$ in distance at a scan frequency of up to 900,000 points per second (Trimble Navigation Limited 2012). The range accuracy of the laser measurement is $0.3-1.1 \mathrm{~mm}$ at $10-25 \mathrm{~m}$ of distance from scanner. The weight is only $5 \mathrm{~kg}$. Trimble RealWorks v.8.1 is used for the initial data processing of point clouds by TX5. The RealWorks software enables not only the initial processing of the raw point cloud data but also the postprocessing including cloud-based registration as noted later.

For each measurement, scanners were placed at multiple positions (4-7 for the target zone of $50 \mathrm{~m}$ by $50 \mathrm{~m}$ ) to obtain the data from different sight of views. The point clouds from different scan positions are then registered to each other by several reference targets, as well as by key morphological features in the point cloud without positional changes such as tree trunks and poles in the surrounding areas. For the matching of the key features, cloud-based registration is applied based on the iterative closest point (ICP) algorithm built in the RealWorks software (Besl and McKay 1992; Bergevin et al. 1996). In this algorithm, one point cloud is fixed as a reference, and another cloud is transformed (shift and rotation) to best match the reference. Overlap areas with the same morphological features for both the reference and moving clouds are necessary to perform the matching. The transformation of the moving cloud is iteratively refined to minimize the distance between closest points in the moving and reference point clouds. The aligned point clouds are finally merged after achieving the least error of the cloud-based registration (at millimeter scales). Such a cloud-based registration method has an advantage in that many tie points (registration targets) are not necessarily set. This process is hereafter referred to as "internal registration." 

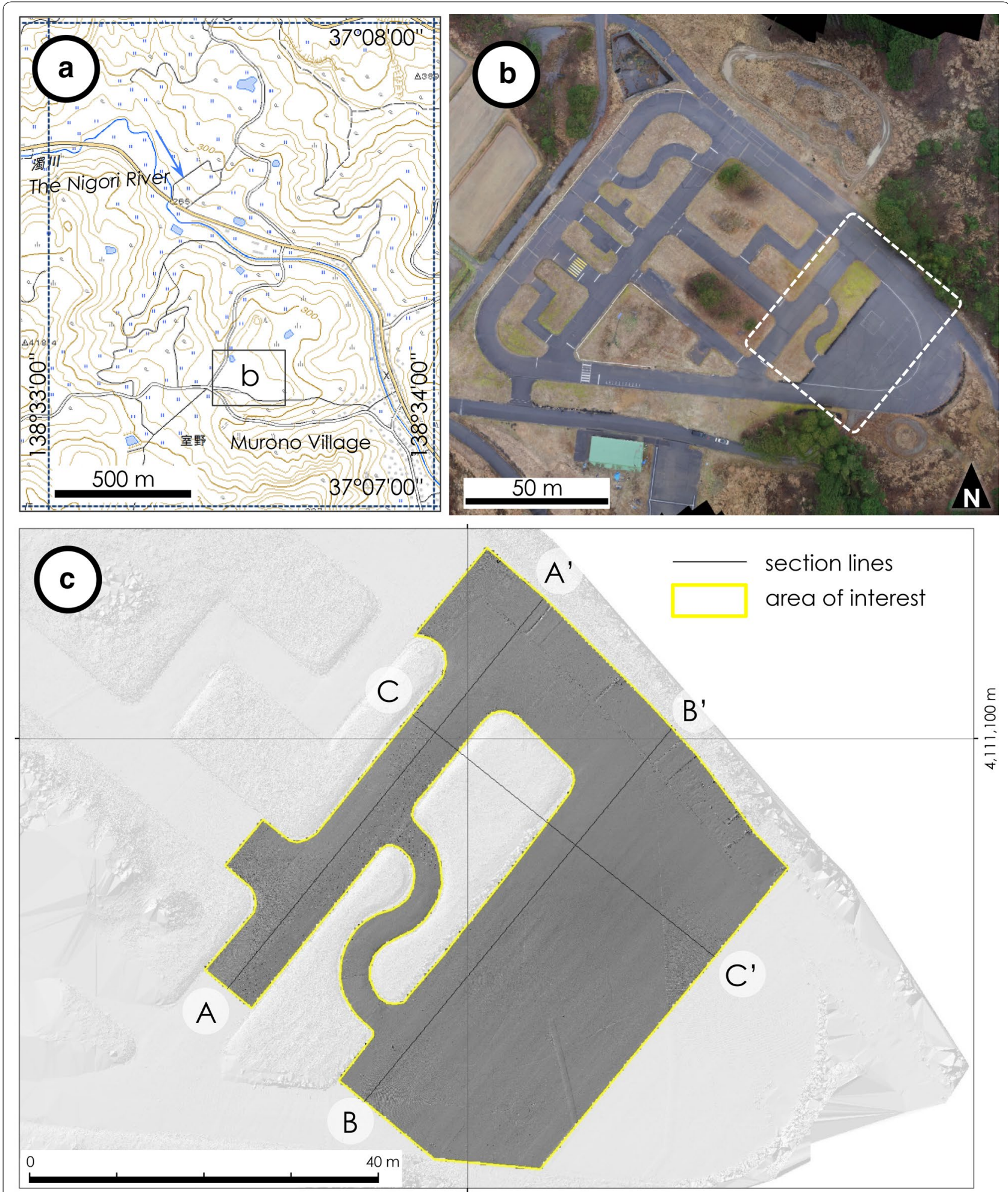

$\varepsilon$
8
8
$\vdots$
$\vdots$
$\bar{\sigma}$

Fig. 1 Study area. a Overview of topographic map (contour interval of $10 \mathrm{~m}$, provided by Geospatial Authority of Japan) showing the location of study area. b Orthorectified aerial photograph of the study area (taken on December 2014). The target zone of TLS measurement (50 m $\times 60 \mathrm{~m}$ ) is shown by a white dashed line. c Masked target area for the analyses. $A-A^{\prime}$ to $C-C^{\prime}$ indicates locations of topographic section lines shown in Fig. 5 . Numbers associated with vertical (N-S) and horizontal (E-W) thin lines indicate grid coordinates on UTM Zone 54N (JGD2000 datum) projection 

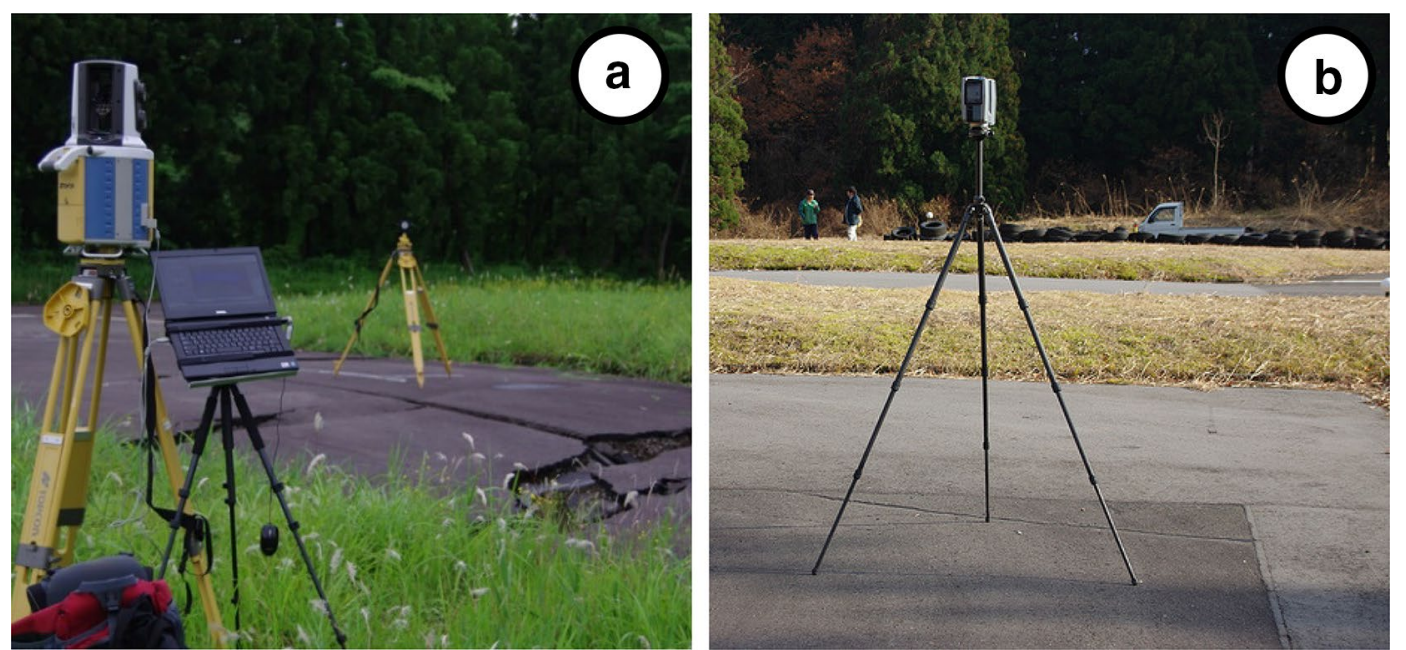

Fig. 2 Terrestrial laser scanners used. a Topcon GLS-1500 (June 2011). b Trimble TX5 (December 2013)

The merged point cloud is then georeferenced using target references whose geographical coordinates are obtained by GNSS measurement (in UTM Zone 54N projection). Checkerboard-type flat targets made by black and white tapes were placed on the paved ground, whose central point was identified in the TLS point cloud using the RealWorks software. The GNSS positioning data are post-processed by carrier-phase correction using a nearby base station data of GEONET (GNSS network in Japan) provided by Geospatial Authority of Japan. Accuracy of the GNSS measurement is on the order of centimeters with the fix solutions after post-processing.

The point clouds obtained at different times can be roughly aligned to each other by the georeferencing process above. However, since some centimeter-scale errors may remain in the GNSS positioning data, the registration is further refined based on the cloud-based registration with the same, unchanged key features in the point cloud using the ICP algorithm, which can reduce the errors down to millimeter scales (e.g., Pesci et al. 2007; Teza et al. 2007). The third measurement dataset (141204) was set as the reference because it showed the best fix-solution accuracy in GNSS positioning for the georeference: $12.1 \mathrm{~mm}$ in $\mathrm{XY}$ and $23.1 \mathrm{~mm}$ in $\mathrm{Z}$ directions with 11 GCP targets. Each of the other datasets is successively aligned to one following dataset. To perform the cloud-based ICP registration, it is important to find overlaps of the same objects in two clouds. The main target area of measurement is therefore cropped out, and stable, unchanged features in surrounding areas are used for the registration. For the best registration accuracy, the ICP registration procedure was repeatedly applied by limiting the overlap areas: Once the moving cloud is registered to the reference cloud, the points that are significantly away from the overlap areas of the moving and reference clouds are excluded, and the ICP registration is again applied. Because the exclusion of points out of the overlap areas forces the remaining points to represent the unchanged features more clearly, repeated application of this process enables to significantly refine the registration. This process is hereafter referred to as "external registration."

The raw point cloud contains some unnecessary points, which can be derived from temporally located materials on ground (e.g., tripods, antenna rods and bags) and/ or materials passing through the laser pulse (e.g., walking person, raindrops, birds and bugs). These anomalous, noisy features are readily removed either by automatic filtering or visual inspection because the presence of those materials is not so frequent during the measurements.

Digital elevation models (DEMs) with a fixed grid size are then generated from the point clouds. The resolution of DEMs is determined based on the spatial density of point cloud data. Although the linear interpolation by triangular irregular network is applied to fill voids, the uncertainty of the interpolation for the areas with insufficient point density is minimal because the target zone is selected with enough point density. Because areas apart from scanner position often have insufficient density of point cloud, those areas are excluded from the following analyses by setting a mask. The mask is also applied to vegetation areas covered by low-height $(<40 \mathrm{~cm})$ plants where the ground surface is rarely detected (Fig. 1c). Within the domain of the analysis, three section lines are set along which topographic profiles are extracted from the DEMs (Fig. 1c). The target area after the masking 
$\left(2038 \mathrm{~m}^{2}\right)$ is therefore smaller than the original point cloud extents.

The difference of DEMs is then computed. The periods of comparison are defined as below: Period I, 110623 to 131205; and Period II, 131205 to 141204. We use ESRI ArcGIS 10.3 software for the DEM data processing.

Since the bulging ground surface has exhibited apparent cracks at the time of measurement 110623, the cracks are traced using the generated DEM of this time. To support the tracing, crack features are highlighted by hillshade image and local variation of elevation $(3 \times 3$ cell statistics) calculated from the DEM.

\section{Results}

Targeting the central zone of deformation, three time series of point cloud data were obtained by the TLS measurements. Table 1 shows the properties of point clouds for each measurement series. The density of the point clouds ranges from 385.6 to $16,253.3$ points per square meters, which are equivalent to average point spacing of approximately $8-51 \mathrm{~mm}$. The resolutions of DEMs are therefore set as $50 \mathrm{~mm}$ for 110623 and $10 \mathrm{~mm}$ for 131205 and 141204 .

As noted, this third measurement dataset (141204) was set as the reference, and each dataset was aligned to one following dataset. The computed error values of the ICP registrations, expressed as an average distance between nearest points in point clouds on the overlap areas (hundreds to thousands for each pair), for the internal registration were $2.9-7.9 \mathrm{~mm}$, while those for the external registration procedure were $6.2-15.7 \mathrm{~mm}$ (Table 1).

The cracks on the paved ground surface found in June 2011 were mapped (Fig. 3). The average direction of the crack lines was found to be $37.5^{\circ} \mathrm{W}$.

Differences in elevation values of the DEMs were computed for each period (Fig. 4). Centimeter-scale vertical changes of the ground surface appear to be spatially variable. Positive changes in elevation for Period I are

Table 1 Point cloud properties obtained by TLS

\begin{tabular}{llll}
\hline $\begin{array}{l}\text { Date of measurement } \\
\text { (YYMMDD) }\end{array}$ & $\mathbf{1 1 0 6 2 3}$ & $\mathbf{1 3 1 2 0 5}$ & $\mathbf{1 4 1 2 0 4}$ \\
\hline $\begin{array}{l}\text { Terrestrial laser scanner used } \\
\text { Number of scan position }\end{array}$ & GLS-1500 & TX5 & TX5 \\
$\begin{array}{l}\text { Internal registration errors for } \\
\quad \text { scan positions (mm) }\end{array}$ & 4.0 & 8.9 & 7 \\
$\begin{array}{l}\text { External registration errors for } \\
\text { time series (mm) }\end{array}$ & 6.2 & 15.7 & - \\
$\begin{array}{l}\text { Number of points used } \\
\text { Point density (pt/m }{ }^{2} \text { ) }\end{array}$ & $1,973,134$ & $130,137,112$ & $102,864,460$ \\
Average point spacing (mm) & 385.6 & $15,516.4$ & $16,253.3$ \\
\hline
\end{tabular}

apparent around the western side of the cracks in 2011 (up to ca. $80 \mathrm{~mm}$ ), whereas some negative changes are also found in the eastern side. Because the paved area with cracks was partially repaired after the 110623 measurement, these patchy decreases in elevation may have derived from such artificial modification. Nevertheless, the apparent increase in elevation is more likely natural changes because it is not realistic to fill up the cracked surface for the repair purpose. Also, anomalously large changes around the corners of the target area are supposed to be the interpolation errors due to insufficient point density, and they are ignored. For Period II, increase in ground surface elevation is clear around the central areas with previous cracks with up to ca. $60 \mathrm{~mm}$, while the easternmost side shows negative changes in the ground surface elevation.

Figure 5 illustrates the topographic profiles of the target area at the different times. In section $\mathrm{A}-\mathrm{A}$, the ground surface elevation seems to have continuously increased since 2011. However, the section B-B' shows decrease in elevation in 2013, which again shows increase in 2014. Such contrasts of the western and eastern sides are also shown in the section $\mathrm{C}-\mathrm{C}$.

\section{Discussion and conclusions}

To find the feasible level of detection of the vertical displacements in the ground surface of the mud volcano, the accuracy of the TLS measurement should be carefully assessed. In general, the measurement accuracy by TLS may be affected by (1) specification of scanner, (2) internal registration, (3) external registration and (4) filtering (Heritage et al. 2009; Hayakawa and Oguchi 2016). The assessment of spatial variability in such errors is also essential for areas with local topographic variations (Heritage et al. 2009; Wheaton et al. 2010; Milan et al. 2011). However, the area of this study has less variation in topographic condition with a smooth, paved ground surface. Because of this condition without significant spatial variability in errors due to the local topographic anomalies, we only consider uniform level of detection for centimeter-scale changes within the target zone.

Among the error sources listed above, the scannerderived error may increase with the elongation of laser footprint due to lower hit angle of laser beams on target objects, as well as the bad reflectance of target material. As noted, the amount of this is given to be $1-4 \mathrm{~mm}$ for the scanners used. Regarding the internal registration errors, the cloud-based ICP refinement gave $2.9-7.9 \mathrm{~mm}$ of fit after repeated refinements (Table 1). Compared to the average point spacing of the point clouds obtained $(7.8-50.9 \mathrm{~mm})$, these values are small enough, whereas the external registration errors after the cloud-based refinement were $6.2-15.7 \mathrm{~mm}$, which are twice as large 


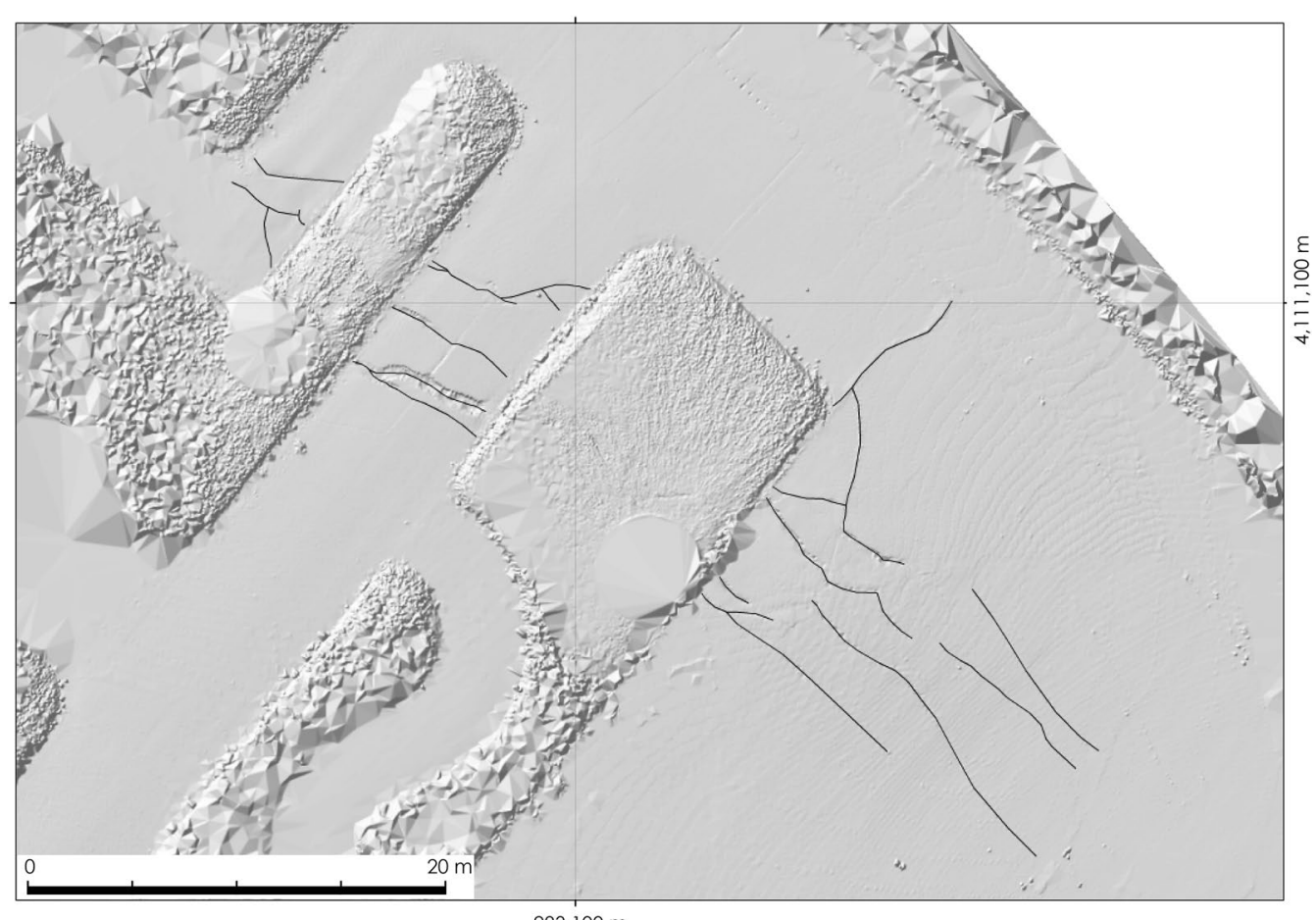

$283,100 \mathrm{~m}$

Fig. 3 Traces of cracks on paved ground surface observed in June 2011. Mean orientation of the lines is N37.5 W

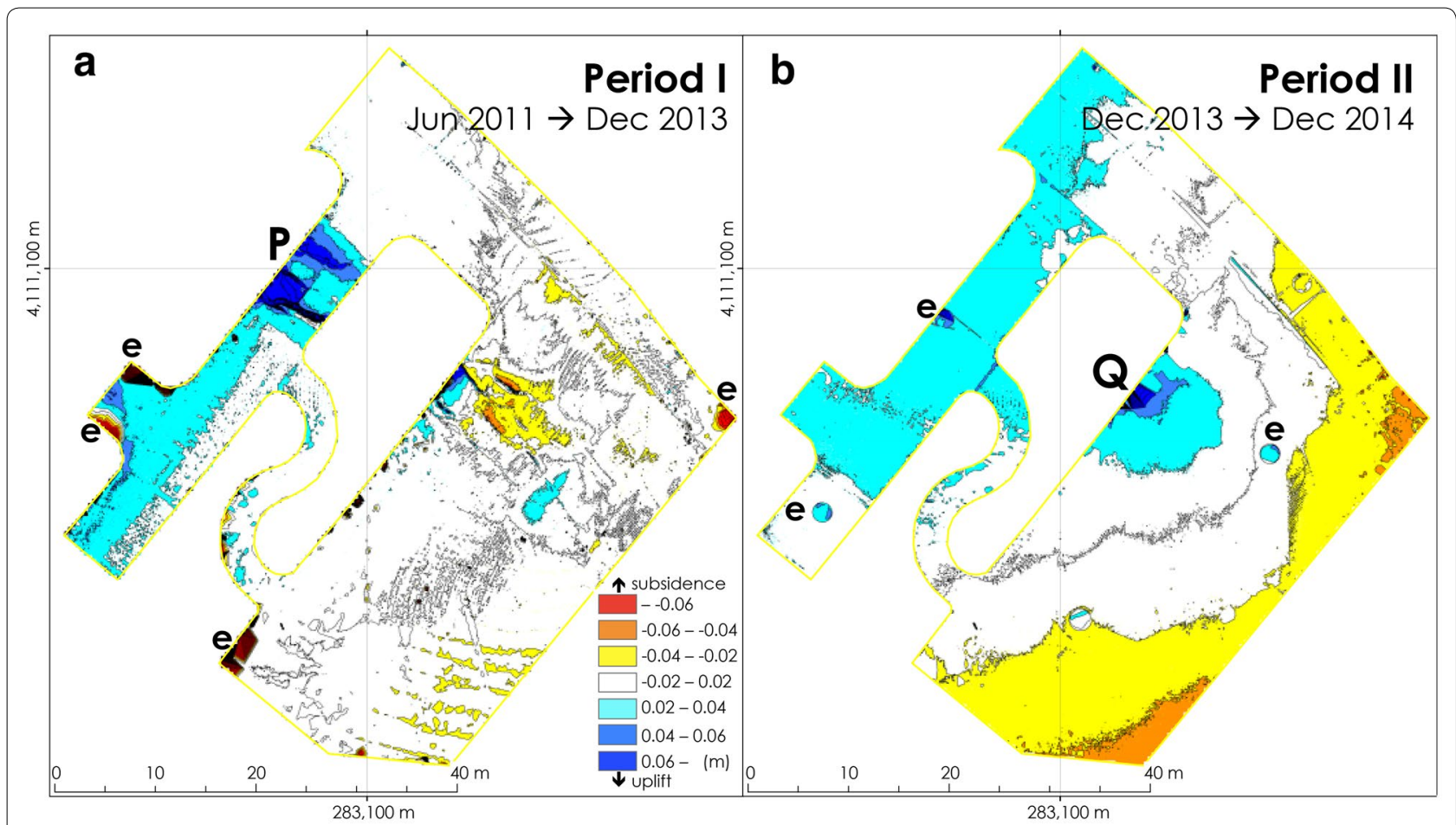

Fig. 4 Differences of DEMs showing temporal changes in ground surface elevation. Blue color indicates uplift, while orange/red color shows subsidence. a Changes in Period I (from June 2011 to December 2013). b Changes in Period II (from December 2013 to December 2014). "P" and "Q" indicate the major uplift area for each Period. "e" shows locations of small artifacts identifiable 

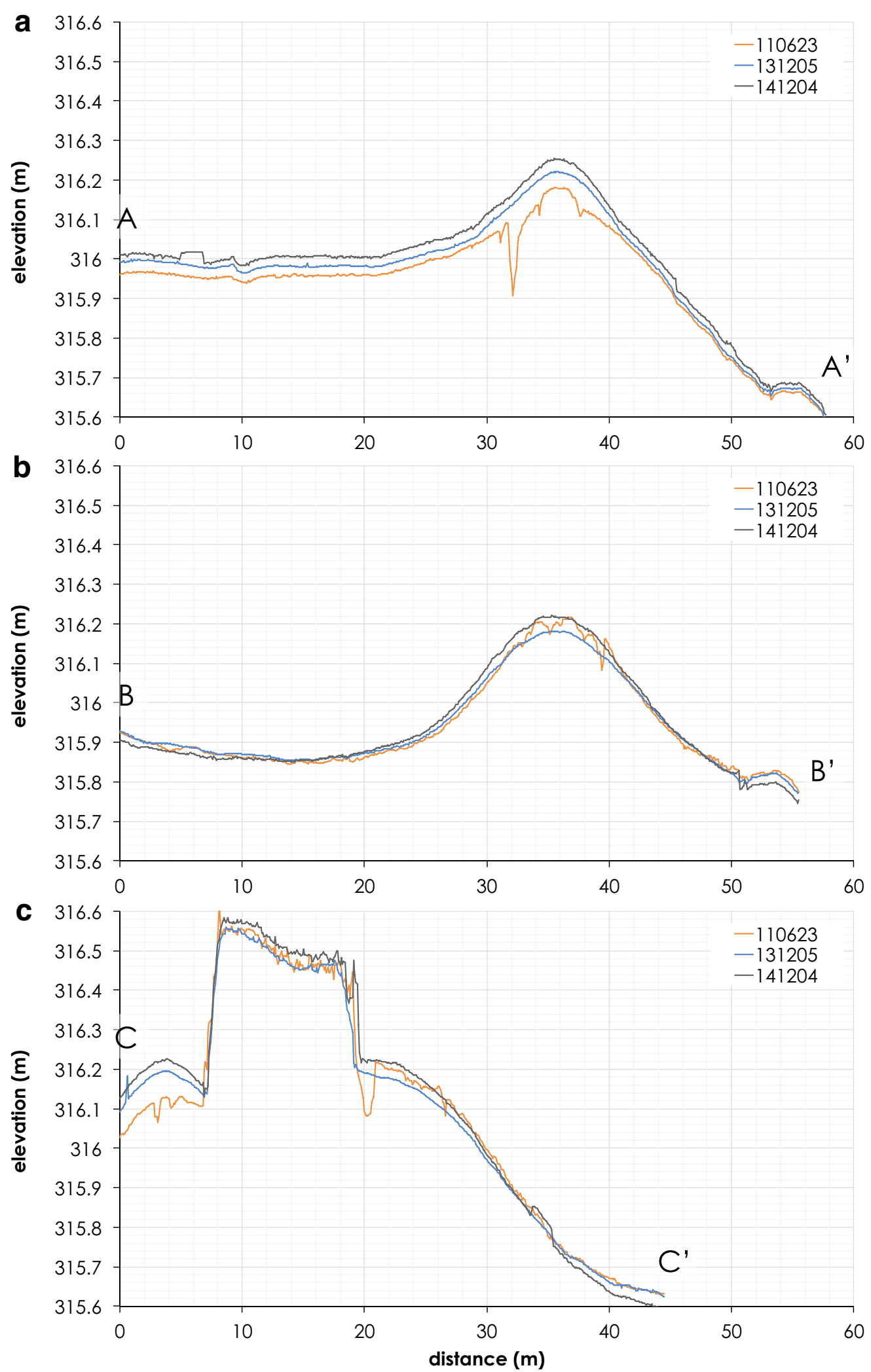

Fig. 5 Topographic profiles of the target zone for the three times of measurements (location of the sections is shown in Fig. 1c). a Section A-A', showing continuous increase. b Section B-B', showing decrease in 2013 and rebound afterward at the main bulge. c Section C-C' 
as the internal registration errors. It is common that external registration gives significantly larger errors than scanner-derived and internal registration errors (Pfeifer et al. 2007), because the point clouds at different times may contain large amount of different features that are natively different. Nevertheless, the external registration errors observed in this study fall in a reasonable range, which is smaller than the average point spacing $(7.8-50.9 \mathrm{~mm})$. Summarizing the error values above as the square root of the sum of squares of maximum error values for each, the overall accuracy of the TLS measurement is supposed to be $18.0 \mathrm{~mm}$. This would be small enough to detect centimeter-scale changes over $20 \mathrm{~mm}$ in the land surface.

In addition, conversion from the point cloud to DEM can also produce some more errors due to inappropriate interpolation between largely spacing points, i.e., in areas with low point density (Heritage et al. 2009). Although such areas are mostly excluded from the analysis of this study, some errors could have remained particularly around the edge of the data extent and at the bottom of scanner where point data cannot be obtained. Because such errors are small and visually identifiable (marked by "e" in Fig. 4), they are simply ignored as noted before.

These accuracies or errors indicate the level of detection plausible by these TLS-derived datasets. Because the error values listed above are maximal in three dimensions including XYZ components, the error values in one component can be similar to or smaller than those values. In Fig. 4, we showed changes over $\pm 20 \mathrm{~mm}$ of $\mathrm{Z}$ component, i.e., vertical displacements, and this was enough to represent the actual vertical displacements which often exceeded this level. Although changes less than a centimeter may be difficult to detect by this method, the TLS approach effectively enables centimeter- to decimeterscale topographic changes.

Compared to the leveling survey, one of the advantages of the TLS measurement is that it can obtain significantly dense points over an area. Because the leveling survey is based on measurements of fixed points whose density is generally sparse, it cannot provide information for a certain distance between points (at least several meters in the case of Kusumoto et al. 2014, 2015), and interpolation is necessary to obtain the intermediate information, whereas the dense point cloud data by TLS $(7.8-50.9 \mathrm{~mm}$ in this study) can provide more aerial information, which enables to show spatial distribution of surficial displacements with direct measurement (Fig. 4). Topographic profiles can also be utilized to help the interpretation of the changes (Fig. 5).

Artificial modification (repair of pavement) after the earthquake-derived deformation has partially applied in the study area. The area of such artificial modification is clearly shown in the data, i.e., the surface in the eastern side of the target area has significantly been smoothed in Period I (Figs. 4a, 5a, c). In this side, the rough surface with cracks found in 2011 has been smoothened and the elevation decreased. Such artificial modification has also been applied to the western side of the target area where the cracks were smoothed (Fig. 5a), although the uplift is more active in this side as noted later.

The deformation of Murono mud volcano has been recognized to be particularly active when large earthquakes occur in this region (Onishi et al. 2009; Kusumoto et al. 2015), while it has been deformed even when without such strong earthquakes (Kusumoto et al. 2014). Kusumoto et al. (2014) reported +26 to $-14 \mathrm{~mm}$ uplift and subsidence by means of leveling survey in June to December 2012, while no particular earthquake was observed in this period. They also reported seasonal variance in the uplift and subsidence throughout the measurement period. Such seasonal fluctuations, as well as the differences in the covering time span [Period I: June 2011 to December 2013, which is much longer than that by Kusumoto et al. (2014)] hinder direct comparison of the amount of displacement. Nevertheless, the spatial pattern of uplift and subsidence within the target seems to correspond well with those reported by Kusumoto et al. (2014) (Fig. 4a): The spatial distribution of the large $(\geq 40 \mathrm{~mm})$ uplift seems to follow the displacement in 2011 as shown in the crack distribution (Fig. 3). This suggests that the activity of the mud volcano similarly continues even after the 2011 earthquake. The amount of maximum total uplift of $\sim 80 \mathrm{~mm}$ in 2.5 years of Period I corresponds to some extent with that in the half a year in $2012(\sim 26 \mathrm{~mm}$; Kusumoto et al. 2014) if they are normalized over time. Such gradual changes are therefore supposed to be accumulated during the quiescent phase.

When the large earthquake in 2014 (Nagano-ken Kamishiro Fault Earthquake) hit the region, the vertical displacement of the Murono mud volcano area was more than $50 \mathrm{~mm}$ (Kusumoto et al. 2015). Period II of this study covers the earthquake event, and the locus of marked uplift observed in this period (Figs. 4b, 5) corresponds well with the point having the highest uplift by the earthquake (Kusumoto et al. 2015). Because the maximum amount of uplift in this Period II (ca. $60 \mathrm{~mm}$ ) is almost the same as or slightly larger than that by the earthquake, it is plausible that the changes in Period II comprise both the activities by the earthquake and in the quiescent phase. Furthermore, the spatial distribution of vertical displacements in this period exhibits oval pattern (Fig. 4b), and the direction of its major axis also corresponds well with those of the cracks $\left(37.5^{\circ} \mathrm{W}\right)$ found in 2011 . Therefore, the activity pattern of the mud volcano by the 
2014 earthquake is supposed to be similar to that by the 2011 earthquake. It is also noted that the largest uplift is observed in the western side in Period I ( $\mathrm{P}$ in Fig. 4a), while that is found in the slightly eastern side in Period II (Q in Fig. 4). This may indicate that the central position of the activity of the mud volcano is being shifted from the west to east side within the target area.

The high-definition data were also quite useful for accurate mapping of small topographic features on the ground including the cracks in the pavement (Fig. 3). Such distinct cracks are well shown in the profiles (Fig. 5), whose depths are identifiable to be $100-200 \mathrm{~mm}$. Although we only focused on the vertical displacements of the ground surface based on DEM analyses, it would also be possible to detect changes of horizontal components if such comparable feature extraction is effectively performed.

In this study, we demonstrated the effectiveness of TLS measurements for the detection of ground surface changes due to underground activities of a mud volcano. The results of error estimates, as well as good accordance with the leveling survey, support the validity of TLS measurements to detect centimeter-scale changes. Repeated measurements will also be taken to further examine long-term activities of the mud volcano. As noted, the TLS approach only provides information on surficial morphology and not internal structures, and mechanical details of the mud volcano remain to be examined. Combinations with other geophysical data will therefore allow us to unravel the subsurface mechanisms of the mud volcano.

\section{Abbreviations}

DEM: digital elevation model; GNSS: global satellite navigation system; ICP: iterative closest point; TLS: terrestrial laser scanning.

\section{Authors' contributions}

YSH performed field measurement by TLS. He also analyzed data and drafted this manuscript. SK obtained permission of the field survey and discussed the results we observed. NM planned the initial field measurement and discussed the results we observed. All authors read and approved the final manuscript.

\section{Author details}

${ }^{1}$ Center for Spatial Information Science, The University of Tokyo, 5-1-5 Kashiwanoha, Kashiwa, Chiba 277-8568, Japan. ${ }^{2}$ Graduate School of Science and Engineering for Research (Science), University of Toyama, 3910, Gofuku, Toyama 930-8555, Japan. ${ }^{3}$ Graduate School of Education, Okayama University, 3-1-1 Tsushimanaka, Okayama City, Okayama 700-8530, Japan.

\section{Acknowledgements \\ This research was partly supported by JSPS KAKENHI Grant Number JP25702014. We used spatial data provided by CSIS Joint Research \#534. We are most grateful to two anonymous reviewers for their constructive comments on the manuscript and to T. Ozawa for his editorial advice and cooperation.}

\section{Competing interests}

The authors declare that they have no competing interests.
Received: 25 March 2016 Accepted: 19 June 2016

Published online: 12 July 2016

\section{References}

Antonielli B, Monserrat O, Bonini M, Righini G, Sani F, Luzi G, Feyzullayev AA, Aliyev CS (2014) Pre-eruptive ground deformation of Azerbaijan mud volcanoes detected through satellite radar interferometry (DInSAR). Tectonophysics 637:163-177. doi:10.1016/j.tecto.2014.10.005

Bergevin R, Soucy M, Qagnon H, Laurendeau D (1996) Towards a general multi-view registration technique. IEEE Trans Pattern Anal Mach Intell 18:540-547. doi:10.1109/34.494643

Besl PJ, McKay ND (1992) A method for registration of 3-D shapes. IEEE Trans Pattern Anal Mach Intell 14:239-256. doi:10.1109/34.121791

DeLong SB, Lienkaemper JJ, Pickering AJ, Avdievitch NN (2015) Rates and patterns of surface deformation from laser scanning following the South Napa earthquake, California. Geosphere 11:1-17. doi:10.1130/GES01189.1

Etiope G, Nakada R, Tanaka K, Yoshida N (2011) Gas seepage from Tokamachi mud volcanoes, onshore Niigata Basin (Japan): origin, post-genetic alterations and CH4-CO2 fluxes. Appl Geochem 26:348-359. doi:10.1016/j. apgeochem.2010.12.008

Hayakawa YS, Oguchi T (2016) Applications of terrestrial laser scanning in geomorphology. J Geogr (Chigaku Zasshi) 125:299-324. doi:10.5026/jgeography.125.299 (in Japanese with English abstract)

Heritage G, Hetherington D (2007) Towards a protocol for laser scanning in fluvial geomorphology. Earth Surf Process Landforms 32:66-74. doi:10.1002/ esp. 1375

Heritage GL, Large ARG (2009) Laser scanning for the environmental sciences. Wiley-Blackwell, New York

Heritage GL, Milan DJ, Large ARG, Fuller IC (2009) Influence of survey strategy and interpolation model on DEM quality. Geomorphology 112:334-344. doi:10.1016/j.geomorph.2009.06.024

Hubbard B, Glasser N (2005) Field techniques in glaciology and glacial geomorphology. Wiley, New York

Kusumoto S, Sudo K, Kawabata M et al (2014) Vertical movement during the quiescent phase of the Murono mud volcano, Niigata, Japan. Earth Planets Space 66:14. doi:10.1186/1880-5981-66-14

Kusumoto S, Hamamoto T, Fukuda Y, Takahashi A (2015) Vertical movements of the Murono mud volcano in Japan caused by the Naganoken Kamishiro Fault Earthquake in 2014. Earth Planets Space 67:53. doi:10.1186/ s40623-015-0223-1

Lane SN, Westaway RM, Hicks DM (2003) Estimation of erosion and deposition volumes in a large gravel-bed, braided river using synoptic remote sensing. Earth Surf Process Landforms 28:249-271

Matta N, Hayakawa YS, Hori Ket al (2012) Uplift of the Matsudai mud volcano associated with the earthquake near the border of Nagano and Niigata Prefectures, measured by 3D laser scanner. Trans Japanese Geomorphol Union 33:94-95 (in Japanese)

McCormac JC, Sarasua W, Davis W (2012) Surveying, 6th edn. Wiley, New York

Milan DJ, Heritage GL, Large ARG, Fuller IC (2011) Filtering spatial error from DEMs: implications for morphological change estimation. Geomorphology 125:160-171. doi:10.1016/j.geomorph.2010.09.012

Mottershead DN, Duane WJ, Inkpen RJ, Wright JS (2008) An investigation of the geometric controls on the morphological evolution of small-scale salt terrains, Cardona, Spain. Environ Geol 53:1091-1098. doi:10.1007/ s00254-007-0736-4

Noda H (1962) The geology and paleontology of the environs of Matsunoyama, Niigata Prefecture, with reference to the So-called Black Shale. Sci reports Res Inst Tohoku Univ 2:199-236 (in Japanese with English abstract)

Onishi K, Sanada Y, Yokota T et al (2009) Investigation of subsurface S-wave Velocity structures beneath a Mud Volcano in the Matsudai-Murono District by surface wave method. Chigaku Zasshi J Geogr 118:390-407. doi:10.5026/jgeography.118.390 (in Japanese with English abstract)

Pesci A, Loddo F, Conforti D (2007) The first terrestrial laser scanner application over Vesuvius: high resolution model of a volcano crater. Int J Remote Sens 28:203-219. doi:10.1080/01431160500534473

Pfeifer N, Dorninger P, Haring A, Fan H (2007) Investigating terrestrial laser scanning intensity data: quality and functional relations. In: 8th Conference on optical 3-D measurement techniques, pp 328-337 
Shinya T, Tanaka K (2009) Origin of materials erupting from Mud Volcano in Tokamachi City, Niigata Prefecture, Central Japan. Chigaku Zasshi J Geogr 118:340-349. doi:10.5026/jgeography.118.340 (in Japanese with English abstract)

Suzuki K, Tokuyasu S, Tanaka K (2009) Underground Structure of Mud Volcanoes in Tokamachi City, Niigata Prefecture determined by electromagnetic exploration, and geographical and geological surveys. Chigaku Zasshi J Geogr 118:373-389. doi:10.5026/jgeography.118.373
Teza G, Galgaro A, Zaltron N, Genevois R (2007) Terrestrial laser scanner to detect landslide displacement fields: a new approach. Int J Remote Sens 28:3425-3446. doi:10.1080/01431160601024234

Topcon (2010) User Manual: Laser Scanner GLS-1500 Series. p 84 (in Japanese) Trimble Navigation Limited (2012) Datasheet Trimble TX5 scanner

Wheaton JM, Brasington J, Darby SE, Sear DA (2010) Accounting for uncertainty in DEMs from repeat topographic surveys: improved sediment budgets. Earth Surf Process Landforms 35:136-156. doi:10.1002/esp.1886

\section{Submit your manuscript to a SpringerOpen ${ }^{\circ}$ journal and benefit from:}

- Convenient online submission

- Rigorous peer review

- Immediate publication on acceptance

- Open access: articles freely available online

- High visibility within the field

- Retaining the copyright to your article 